\title{
Sharing Personalised Books: A Practical Solution to the Challenges Posed by Home Book Reading Interventions
}

\author{
Natalia Kucirkova, David Messer, Denise Whitelock \\ The Open University, UK
}

\begin{abstract}
The proposed project addresses the recently introduced claim that the socio-cultural relevance of parent-child engagement in home book reading needs to be at the heart of new interventions in this area. The rationale for this project was to offer a practical solution to concerns about the challenges posed by traditional shared book reading interventions and about the need to take account of multiple, rapidly changing home learning environments. The proposed project brings together this broad range of issues by evaluating the benefits and effectiveness of an intervention which uses selfmade personalised books, in various formats, languages and forms. As such, the project acknowledges the socio-cultural variety of home learning environments and taps into the motivational issues for parents' (non)participation in traditional early book intervention programmes. In this paper, we identify the project's core principles, concentrating on two major tenets of the study: Firstly, the importance of story book sharing being personally meaningful to both parents and children, and secondly, the socio- cultural and temporal relevance of a home book reading intervention.
\end{abstract}

\section{Introduction}

In light of the recent Anglo-American family policy developments targeting literacy education in disadvantaged groups [1], there has been significant government interest in supporting home learning environments. As a result, in the last two decades, numerous early intervention programs have emerged, supporting parents to become their children's educators and early literacy instructors. The rationale behind most of these interventions is based on:

- the importance of harnessing parents as their children's first and foremost source of education;

- preventing the education gap between disadvantaged and more advantaged children, and;

- recognition of the importance of literacy to access virtually all areas of the curriculum. Given the recognised importance of parents in their children's development, the first premise has been widely accepted in Western countries. The second premise has been recently challenged by professionals, calling for a thorough cost/benefit evaluation of some of the interventions [2]. While debates continue about the value of early intervention programmes for overall long-term socio-cognitive benefits for children, a substantial body of evidence indicates there are real benefits of book reading interventions for children's language and literacy development [3]. These benefits are particularly pronounced for children from disadvantaged backgrounds, who have been reported to have lower levels of language ability than their more advantaged peers [4]. This is of concern given that vocabulary and literacy have been shown to be critical components of children's educational progress. Vocabulary is often seen as providing the essential basis for communicative development [5] and for children's reading [6], while reading ability is fundamental to being able to make gains at school and in life more generally [7]. Clearly, the factors influencing the development of language and literacy are complex and multi-faceted, but there also is a substantial body of evidence which identifies several areas which are important for the development of these abilities. These are: (i) motivating carers to make 'learning' a social and enjoyable experience; (ii) increasing and consolidating the child's vocabulary, and (iii) focused exposure to written materials in a positive and supportive environment. One learning situation which appears to provide an especially suitable context for all these factors is shared book reading.

\section{Shared book reading interventions: study rationale}

Parent-child shared book reading has been identified as a 'literacy event par excellence' [8 p.380], resulting in effective language learning [9] and in the development of a number of early literacy skills, including children's awareness of print [10], modulation of joint attention [11] and children's vocabulary growth [12]. It also aids in a positive parent-child relationship, which can further enhance the learning experience. In 
Western countries, the activity is widely regarded as universally beneficial and 'the way into literacy' [13 p.82]. As a result, most parent-child early literacy interventions have been designed to contain a 'book reading element'. Typically, the research and policy efforts in this area focus on ways of how to maximize the benefits of this activity, i.e. working in a deficient hypothesis paradigm.

In the UK and US, parents' involvement has been sought through interventions aimed at increasing the quantity of books at home (and through this process, the frequency of reading). Various non-profit organizations work on the premise that sending free books to parents' homes increases children's chances to succeed in literacy (e.g. the Dolly Patron library). Also, national government initiatives such as Bookstart in the UK became popular and showed success in promoting children's reading and cognitive development [14]. On the other hand, the quality of the activity has been the target of some research efforts. Typically, these aims to enrich home book reading by teaching parents specific techniques linked to child's enhanced language development. An oftencited quality reading intervention program is dialogic reading, developed by Whitehurst and colleagues [15]. In dialogic reading, parents are instructed to use among others, open-ended questions, expansions and attribute questions which are known to increase children's expressive vocabulary [16].

The above dichotomous approaches have usually had a narrow focus on either quality or quantity of book reading (or specific elements of each), and consequently, have failed to encompass the richness of the parent-child interaction resulting from storybook sharing. There is evidence that a specific reading style does not help all children and that what works for some, may not work for others. As an example, Reese and Cox [17] identified three main reading styles in parents: comprehenders, describers or performance-oriented parents. Although children of parents using the describer style showed highest gains in vocabulary and print skills across time (i.e. a style similar to the one promoted by dialogic reading), the performanceoriented style proved to be beneficial when accounting for children's skills levels at the start of the study.. Thus, different children may benefit from different types of book reading interaction and there are important variations in book reading styles within as well as across families.

In addition, little is known about the response rates and response patterns of parents to books chosen and recommended for them (cf. Books for Babies). Some parents, especially those coming from non-mainstream and often lower socioeconomic class, can find such schemes inappropriate and difficult to engage with. The literature reveals rather that 'it may not be the differences in access/quantity or types of texts that mark critical distinctions among literacy environments' [18p. 110]. It appears that the most pronounced differences reside in parents' beliefs of what constitutes appropriate parent-child interaction, rather than access to books, i.e. an issue unlikely to be resolved through a global approach. This raises further questions about the socio-cultural relevance of universal approaches to home book reading. From anecdotal accounts we found that paradoxically, those who might benefit from book reading the most, seem to be the least aware of the benefits of book reading.

\section{Study objectives}

We believe that neither 'one for all', nor a 'books for all' approach is any longer tenable in the international, rapidly changing home learning environments. Rather, the research efforts and practice in this area should be guided by a thorough consideration of the socio-cultural variability of each family interaction dynamics and literacy preferences. An innovative approach in this area needs to appreciate that because of the rapidly changing socio-economic circumstances, the level of informal learning and literacy in families is continually shifting [19]. Last not least, the access and economic sustainability of a book reading programme should be at the core of a $21^{\text {st }}$ century early literacy intervention.

We believe that the basic assumptions from which to develop a new intervention framework in this area are the socio-economic viability and appropriateness of the intervention, coupled with sound research evidence of 'what works'. For the latter, we do not mean 'what works for some' (notably mainstream middle-class North American or Europeans) but rather what works for the majority of children, regardless of race, ethnicity or socio-economic difference.

Despite the challenging nature of these ideas, there seems to be one aspect inherent in the storybook sharing which unifies them. There is one underlying tenet which is fundamental to an efficient and enjoyable learning process: personally meaningful information [20]. Personally meaningful became the guiding principle of our work and below, we briefly give our line of arguments which connects our approach to the challenges currently faced in early literacy interventions.

\section{Personalised books}

Personally meaningful events involve an individual's unique knowledge and experience, with the result that they are usually of significance and interest to the individual. The principle of 
personalized learning is closely related to this concept, with the aim to 'build a sense of selfactualisation, self-realisation and self-enhancement' [21, p.113]. Personalised information enables enhanced understanding (the learner is building on previous knowledge and known concepts) with reduced memory load. When applied to story sharing, personalised stories could play a crucial role in fostering socio-cognitive skills and help develop relationships. Personalised stories, i.e. stories about what've lived and experienced, constantly help us make sense of our lives. We all share such stories all the time, in everyday life, regardless of culture, ethnicity, class or gender. Although each individual's stories vary in terms of how much 'factual or fictional' they are, they always seem to fulfil one basic function: to 'forge relationships and facilitate language skills' [22, p.19]. This basic function of personal narrative is not only 'culturally universal' [22, p.1] but also the fundamental aim of parent-child book reading interventions. The focus on personalised stories, celebrating each parent's and child's 'funds of knowledge' [23], marks a shift in the philosophical focus of an early literacy intervention. Notably, by directing the theoretical focus toward the unique skills and knowledge produced within the interaction of story sharing, we move away from a deficiency paradigm. Instead of assuming a 'deficiency' - be it material or intellectual- in the home learning environments, our approach is marked by an emphasis on the socio-cultural relevance of the intervention. This thinking is underpinned by two major schools of thought: Lev Vygotsky's and Paulo Freire's educational theories.

\section{Theoretical insights informing our study}

Vygotskian perspectives focus on the social context in which communication and literacy events take place. From a socio-constructivist view, shared book reading can be conceptualised as a form of social interaction context and the role of parent as a 'more knowledgeable other'. The parent assists his or her child to participate in the book reading activity, scaffolds the conversation and guides the language interchange. This proceeds best in what Vygotsky calls 'the zone of proximal development, defined as the difference between the child's actual and potential level of development [24]. Further elaborations of Vygotsky's zone of proximal development involve the suggestion that the most effective learning occurs in the 'region of sensitivity', just a little ahead of child's independent, spontaneous performance. Instructing within the region of sensitivity requires the parent to gradually reduce or increase his support following child's success or failure (the so-called contingency rule; see [25]). As such, Vygotsky and
neo-Vygotskian models of parent-child interaction provide conceptual framework for evaluating adult's role in shared book reading, especially the ability to sensitively and purposefully mediate the meaning of a story to the child. The socio-cultural perspective adopted in later extensions of Vygotskian theory [26; 27] places emphasis on culturally constructed tools and shared meaning; personalised books are particularly suitable in facilitating social interaction which involves these processes.

The notion of knowledge being socially constructed is expanded by the Transformative approaches to pedagogy [28], and theoretical perspectives developed by Paulo Freire [29]. This involves the claim that, the process of gradually constructed knowledge becomes self-evident, as does the argument for meaningfulness and personalization of knowledge. Namely, any learning occurring in the context of book reading is a social process, drawing on three sources of cultural and linguistic capital: 1, the parent, 2, the child and 3, the book's authors. As such, the construction of 'valid knowledge' is a collective and to an important degree, personal process, generating different dynamics for each parent and child. Taking initiative to empower the disadvantaged to participate in knowledge creation is, according to Freire, using literacy education as a 'vehicle by which the oppressed are equipped with the necessary tools to reappropriate their history, culture, and language practices' [30, p. 142). Through this lens, the importance of one particular reading style or of a pre-selected book soon becomes relativisized.

\section{Personally meaningful books}

In light of these theoretical considerations and our colleagues' findings, it seems reasonable to expect that personally meaningful stories turned into a book reading event will enhance the stories' value and learning potential. Moreover, we consider it likely that books based on personalized stories will offer several practical solutions to the intellectual and practical challenges posed by shared book reading interventions. Personalised books are based on pictures and words taken and written by those who know their children best their parents, or caregivers. This can harness parents' investment in doing something valuable for their children and in this process, promote positive parent-child interactions. Further, if each book is tailored to each child's personal interests, needs and culture, it is very likely to elicit substantial interest and engagement of both participants. Books created by parents for their children are intrinsically 'theirs', i.e. entirely relevant in terms of any demographic differences. As such, they are unique in their emphasis on inclusivity of ethnicity, culture, 
gender, and class and the ways these differences constitute new forms of literacy. Self-made books also make use of parents' and if structured appropriately, community resources, significantly bringing down the overheads of an intervention. In a broader sense, through the lens of self-made books, the meaning of parents' unique knowledge is realised by taking account of the broader context of community life [31].

Central to these considerations are projects which involve 'socio-culturally sensitive' early literacy interventions. In these interventions, selfmade books are employed to promote the use of language of the home and forging stronger links between home and school through the use of books. Importantly, books created by children and parents were found to promote children's language skills and lead to enjoyable and meaningful parent-child shared book reading interactions [32]. However, from a research perspective, what remains unclear is the 'vital factor' which resulted in the very positive parent-child book sharing interactions: is it the empowerment of parents in doing something valuable for their children, which translates into increased motivation to use and engage in these literacy activities? Or is it children's fascination with seeing a book based on their own or their parents' lives and experiences? Or is it the excitement of sharing a book of an alternative book format, i.e. the novelty effect? Or is it a combination of all factors?

To begin to test these ideas, we have looked in detail at the engagement patterns of parents sharing self-made personalized books with their babies (1836 months old). In our study, we compared parents' and children's engagement when sharing: a personalised; a non-personalised, and child's favourite book. The personalised and nonpersonalised books were matched in terms of content and format, but differed by information being personal to the child (for example in the personalised book there were pictures featuring child's teddy rather than 'any teddy' as in the nonpersonalised book). Analyses of the data showed (Kucirkova et al., in preparation) that there was an increase in parents' and some forms of children's engagement when reading personalized books, as opposed to books based on what children like (nonpersonalised books) or parents deemed appropriate (child's favourite book). The finding that personalised as opposed to non-personalised books lead to greater parent-child specific and overall engagement was important because it refined the concept of our understanding of 'personally meaningful' and, at the same time, gave room to widen our research agenda. Namely, for parents and children to be most engaged, the book being shared needs to be truly, not just superficially personalised (by e.g. by merely incorporating socio-culturally relevant material).
Thus, personalised books seem to be well suited to challenging the notion of 'universal truth' of knowledge and at the same time, provide an economically sustainable alternative to books gifting schemes relying on donor or government funds. However, if we accept that there are multiple forms of literacy experiences [33], and that knowledge is a socially constructed product of each individual's unique relationships with the world around them, then we also need to acknowledge the varied forms personalized books can take. Illustrative of our broadened agenda is a full consideration of 'truly personalised' books, that is to say including the many and varied forms of literacy which are evident within and across individual families.

Little is known about the benefits and effectiveness of written personal stories in nontraditional book forms. The research literature on the use, effectiveness and benefits of highly technology-motivated and technology-rich home learning environments is just emerging. In order to respond to calls for interventions which, stress multiple forms of engagement and cater to the needs, values, and preferences of the families and communities being served' [34, p.367], we have begun to explore personalised books which make use of the latest cultural tools and technological developments.

\section{Personally meaningful electronic books}

A traditional paper-and-pencil method of book making is becoming less relevant for the highly aesthetic and efficient digital learning environments of parents and children in our society. In order to adapt our ideas to the current social and economic conditions, we have sought to develop some new approaches to investigate digital personalised stories. Two main avenues are described here, which are based on fruitful collaborations with early childhood professionals and experts in digital learning technologies.

The first avenue we explored were electronic books, i.e. self-made books available online, created through easy-to-use software (RealeWriter). The efficient user interface and usability of this software was informally evaluated through its use with seven parents who were encouraged to create books for their babies (Kucirkova et al., in preparation). We became interested in the long-term use of such books, which generated further research questions and interest. In addition, the widespread use and ownership of mobile phones across socioeconomic groups has resulted in our interest in the use of this technology and its potential to motivate parents to create their own stories via pictures taken by their mobile phones. In parallel to this project, we have been developing an iPhone application, 
which allows its users create and write stories using their own pictures downloaded or taken by the iPhone. The application further develops the idea of easy storage and sharing of personalized stories and the multitude of forms and formats they can take. This format also has the potential for the exchange of stories between carers and the development of elearning and digital communities

By looking at various formats of personalized books - be it via applications on smart devices, electronic books on the computer or in their traditional paper form - we have endeavoured to acknowledge parents' multiple book-engagement preferences, as well as the varying resources at their disposal. We also have sought to remediate the research gap in relation to practical solutions of how to use and create personally meaningful, selfmade books. What remains to be explored is the 'power' of personalised books to achieve traditional end results of shared book reading, i.e. to foster children's socio-cognitive skills and positive parent-child relationships.

\section{Future work}

Our investigation is at an early stage with our ultimate objective the design of a practical and efficient family based early literacy intervention. We plan to evaluate whether personalised story of various kind, is beneficial and appropriate for parents and children. Or, to put it more broadly, we plan to challenge the notion that supporting meaningful story sharing in a focused and supportive learning environment facilitated by the written form of stories, may represent viable alternative to the currently employed home book reading interventions.

Self-made personalized books in all their possible forms and formats will be investigated, underpinned by our commitment to an all-inclusive way of parents' and children's engagement in meaningful story sharing.

The planned project results fit with the current recommendations for socio-culturally parenting interventions and are likely to be of interest to policy makers, early years professionals and ultimately, researchers and parents.

\section{Conclusion}

Parent-child shared book reading constitutes an exemplary early literacy intervention. The sociocultural relevance and economical sustainability of previous interventions has begun to be questioned by researchers. We have argued that there is a need to develop and evaluate interventions which are based around personalised books, as these are more likely to engage children and parents in contrast to interventions which simply provide books for families, or simply providing recommendations from experts about the 'best' way to carry out activities which may not suit the child or the family. We believe that these books promote enjoyable parent-child interaction, are reflective of sociocultural considerations, provide individualised contexts of learning and have heightened relevance to children. All this should lead to frequent, focused story sharing, and in turn, to positive parent-child relationship and child's increased socio-cognitive skills. By identifying the important design considerations in this area, our work provides a practical framework in which to consider the current need to realize the full potential of parentchild meaningful story sharing. The planned investigations will evaluate the view that personal stories shared through books (be it in their paper or digital form) have the potential to harness special benefits which go beyond those usually found in shared book reading, while recognising the power of family multimodal literacy resources and giving rise to meaningful parent-child interactions.

\section{Acknowledgements}

We would like to thank Paul Hogan from kMi for his help in developing the iPhone application and Mark Condon and Prof Colin Harrison for their help with the RealeWriter software.

\section{References}

[1] J. Currie, "Early Childhood Education Programs", Journal of Economic Perspectives, 15, 2, 2001, pp. 213238.

[2] J. Belsky, D.Vandell, M. Burchinal, K. A. ClarkeStewart, K. McCartney and M. Owen, "Are there longterm effects of early child care?”, Child Development, 78, 2007, pp. 681-701.

[3] M. Senechal, "Testing the home literacy model: Parent involvement in kindergarten is differentially related to grade 4 reading comprehension, fluency, spelling, and reading for pleasure", Scientific Studies of Reading, 10, 2006, pp. 59-87.

[4] A. Locke, J. Ginsborg, and I. Peers, "Development and disadvantage: implications for the early years and beyond", International Journal of Language and Communication, 37, 1, 2002, pp. 3-15.

[5] V. Muter, C. Hulme, M. J. Snowling, and J. Stevenson, "Phonemes, Rimes, Vocabulary, and Grammatical Skills as Foundations of Early Reading Development: Evidence From a Longitudinal Study”, Developmental Psychology, 40, (5), 2004, pp. 665-681.

[6] D.J. Messer, The Development of Communication: From Social Interaction to Language, Chichester, England: John Wiley \& Sons, 1994.

[7] M. Senechal, G. Ouellette, and D. Rodney, The misunderstood giant: On the predictive role of early 
vocabulary to future reading. In S.B. Neuman \& D.Dickinson (Eds.), Handbook of early literacy research: Vol. 2 (pp.173-182). New York: Guilford Press, 2006.

[8] A. Pellegrini, “A Critique of the Concept of At Risk as Applied to Emergent Literacy”. Language Arts, 68, 1991, pp. 380-85

[9] J. Karrass, and J. Braungart-Rieker, "Effects of shared parent-infant book reading on early language acquisition”, Applied Developmental Psychology, 26, 2004, pp. 133-148.

[10] G.J. Whitehurst, F.L. Falco, C.J. Lonigan, J.E. Fischel, B.D., DeBaryshe, M.C. Valdez-Menchaca, and M. Caulfield, "Accelerating language development through picture book reading", Developmental Psychology, 24, 1988, pp. 552-559.

[11] M. H. Bornstein, and C.S. Tamis-LeMonda, "Maternal responsiveness and infant mental abilities: Specific predictive relations", Infant Behavior \& Development , 20 (3), 1997, pp. 283296.

[12] D.Z. Kassow, "Parent-Child Shared Book Reading Quality versus Quantity of Reading Interactions between Parents and Young Children”, Talaris Research Institute, 1,1, 2006, pp. 1-9.

[13] L. Phillips, S. Norris, and J. Anderson, "Unlocking the door: Is parents' reading to children the key to early literacy development?”, Canadian Psychology/Psychologie canadienne, 49, 2008, pp. 82-88.

[14] B. Wade, and M. Moore, "A Sure Start with Books”, Early Years, 20, 2, 2000, pp. 39-46.

[15] G. Whitehurst, F. Falco, C. Lonigan, J. Fischel, B. DeBaryshe, M. Valdez-Menchaca and M. Caulfield, "Accelerating language development through picture book reading”. Developmental Psychology, 24, 1988, pp. 552-559.

[16] C.E. Huebner, "Promoting Toddlers' Language Development Through Community-Based Intervention”, Journal of Applied Developmental Psychology, 21, 5, 2001, pp. 515-535.

[17] E. Reese and A. Cox, "Quality of adult book reading affects children's emergent literacy”. Developmental Psychology, 35, 1999, pp. 20-28.

[18] N. Roser, Talking over books at home and in school, in Dunsmore, K. And Fisher, D. (eds), Bringing Literacy Home, International Reading Association, 2010.

[19] N. Frey, Home is not where you live but where they understand you, in Dunsmore, K. And Fisher, D. (eds), Bringing Literacy Home, International Reading Association, 2010.

[20] D.G. Myers, Psychology in Everyday Life, New York, Worth Publishers, 2008.

[21] C. Leadbbeater, The future of public services: personalised learning, in Personalising education,
Schooling for Tomorrow, Centre for Educational Research and Innovation, OECD, 2010.

[22] A. McCabe, Chameleon readers: teaching children to appreciate all kinds of good stories, McGraw hill: The University of Michigan, 1995.

[23] L.C. Moll, C. Amanti, D. Neff, and N. Gonzalez, "Funds of knowledge for teaching: Using a qualitative approach to connect homes and classrooms", Theory into Practice, 31, (2), 1992, pp. 131-141.

[24] L. Vygotsky, “Thought and language”. Annals of Dyslexia, 14, 1964, pp. 97-98.

[25] D. Wood, J. Bruner and G. Ross, "The role of tutoring in problem solving”. Journal of child psychology and psychiatry, 17, 1976, pp. 89-100.

[26] C.K. Crook, Learning science and learning technology: a place for cultural psychology. British Journal of Educational Psychology Monograph Series 2, (5), 2007, pp. 1-17.

[27] B. Rogoff, C. Goodman Turkanis, L. Bartlett, Learning Together: Children and Adults in a School Community, Oxford, Oxford University Press, 2002.

[28] J. Cummins, J. and D. Sayers, Brave New Schools: Challenging Cultural Illiteracy Through Global Learning, New york: Palgrave Macmillan, 1997.

[29] P. Freire, Pedagogy of the oppressed, New York: Continuum, 1970.

[30] P. Freire and D. Macedo, Literacy: reading the word and world, London, routledge, 1987.

[31] L.C. Moll, and J. Cammarota, Cultivating new funds of knowledge through research and practice. in Dunsmore, K. And Fisher, D. (eds), Bringing Literacy Home, International Reading Association, 2010.

[32] J. Bernhard, A. Winsler, C. Bleiker, J. Ginieniewicz, and A. Madigan, "Read My Story!" Using the Early Authors Program to Promote Early Literacy Among Diverse, Urban Preschool Children in Poverty”, Journal of Education for Students Placed at Risk (JESPAR), 13, 2008, pp. 76-105.

[33] D. Yamada-Rice, "Beyond words: An enquiry into children's home visual communication practices”, Journal of early Childhood Literacy, 10, (3), 2010, pp. 341-363.

[34] D. Rosen, Book Review: K. Dunsmore, K. And Fisher, D. (eds), Bringing Literacy Home, International Reading Association, 2010, Journal of Early Childhood Literacy, 10, (3), 2010, pp. 364-376. 